\title{
Successful Engraftment of HLA-matched Peripheral Hematopoietic-stem-cell Transplantation for Severe Aplastic Anemia With Multidrug-resistant Bacterial and Fungal Infections
}

\section{Hua}

Hemopoietic Stem Cell Transplantation Center, Fujian Medical University Union Hospital https://orcid.org/0000-0001-8634-061X

Hua Li

Hemopoietic stem cell transplantation center, Fujian Mediacal University Union hospital Xiaofan Li

Hemopoietic stem cell transplantation Certer, Fujian Medical University Union Hospital

\section{Xianling Chen}

Hemopoietic Stem Cell Transplantation Center, Fujian Medical University Union hospital Nainong Li ( $\sim$ NainongLi@163.com )

\section{Case report}

Keywords: Severe Anemia plastic, Severe infection, multidrug-resistant bacteria, Stem cell transplantation

Posted Date: July 9th, 2020

DOI: https://doi.org/10.21203/rs.3.rs-40623/v1

License: (c) (i) This work is licensed under a Creative Commons Attribution 4.0 International License. Read Full License 


\section{Abstract}

Allogeneic hematopoietic-stem-cell transplantation (HSCT) is relatively challenging for the patients with serious infection and intensifying complications. Patients often lost the timing of HSCT due to the poor health status. We report a rare case of successful engraftment of HLA -matched peripheral hematopoietic stem cells for a 15-year-old girl with severe aplastic anemia (SAA), suffering multidrug-resistant (MDR) bacterial infection and fungal infections. With strong antibiotics and life support treatments, the patient received Cy + ATG precondition. The patient received cyclosporine A, methotrexate and mycophenolate for GVHD prophylaxis. Leukocyte and Platelet engraftment occurred on day +15 and +35 respectively. The patient's blood routine test returned to normal on day +72 . The conditioning regimen was well tolerated by patient. Donor's engraftments were achieved successfully. The immunosuppressants were weaned off gradually. We hope this case's experience can be a reference for patients with SAA suffering severe infection on HSCT in future.

\section{Background}

Severe aplastic anemia (AA) is a rare and potentially fatal disease characterized by hypocellular bone marrow and pancytopenia. The major signs and symptoms of $A A$ are severe infections, bleeding, and exhaustion. The diagnostic criteria of severe AA (SAA) according to the British Society for Hematology (2016) require a cellularity of $<25 \%$ in bone morrow biopsy specimens, absolute neutrophil count (ANC) of $<0.5 \times 10^{9} / \mathrm{L}$, platelet count of $<20 \times 10^{9} / \mathrm{L}$, and reticulocyte count of $<20 \times 10^{9} / \mathrm{L}$. Very severe $A A$ (VSAA) is diagnosed when all criteria for SAA are met with a neutrophil count of $<0.2 \times 10^{9} / \mathrm{L}$ [1]. Infection is a significant cause of death in patients with AA. First-line allogeneic hematopoietic-stem-cell transplantation (HSCT) with human leukocyte antigen (HLA)-matched-sibling donor (MSD) is a treatment for newly diagnosed patients with severe AA. When MSD is unavailable, first-line treatment with ciclosporin and/or antithymocyte or antilymphocyte globulin (as first-line immunosuppressive therapy) is an alternative to MSD-HSCT. Long-term neutropenia from SAA increases a patient's risk of infection, which is life threatening. Invasive fungal infections (IFIs) are increasingly being recognized as a common threat in patients with $A A[2,3]$. The incidence and severity of infection are inversely proportional to absolute granulocyte count and duration. Thus, most patients with AA suffer from infectious diseases until neutrophil recovery. The existence of active infection is generally perceived as an obstacle to conventional allogeneic HSCT. Therefore, the timing of allogeneic stem-cell transplantation for infected patient with severe AA is extremely important. At present, no well-documented guidelines of HSCT for severe active infection with AA are available. Here we report a rare case of successful engraftment of HLA-matched peripheral hematopoietic stem cells for a 15-year-old girl with severe AA, suffering multidrug-resistant (MDR) bacterial infection, and IFI.

\section{Case Report}

The girl was diagnosed with VSAA at the age of 15. Acute nonjaundice hepatitis of unknown cause with pancytopenia was found before VSAA diagnosis. Her health was normal until the diagnosis of AA with 
unknown reason. An initial complete blood cell count gave the following results: white blood cell count of $0.19 \times 10^{9} / \mathrm{L}$, ANC of $0.11 \times 10^{9} / \mathrm{L}$, hemoglobin level of $76 \mathrm{~g} / \mathrm{L}$, and platelet count of $12 \times 10^{9} / \mathrm{L}$. Bone marrow biopsy confirmed the diagnosis of severe AA. The patient had normal testing for PNH and cytogenetic studies and received immunosuppressive (i.e., cyclosporine A [CSA]) and hematopoiesis treatment (i.e., G-CSF, TPO, and danazol) after admission. However, the treatment had no significant response, and the patient remained platelet and red blood cell transfusion-dependent for one month. The patient developed pulmonary infection with MDR bacteria and fungus, with an aspergilloma and large number of pleural effusions (Figure 1A). The antibiotics fosfomycin, polymyxin, meropenem, voriconazole, and micafungin could not stop her fever, coughing, and shortness of breath. Sputum culture repeatedly showed Pseudomonasaeruginosa resistance to multidrug. A conventional microdilution assay (CLSI methodology) showed the MICs of imipenem and meropenem at 8 and $>16$, respectively. Given persistent uncontrolled infection, $2.5 \mathrm{~g} / \mathrm{kg}$ Ceftazidime Avibactam Sodium (i.v. q8h) was added to $4 \mathrm{~g}$ fosfomycin (bid, i.v.), with the continuation of voriconazole and liposomal amphotericin B. At the same time, the continuous drainage of the pleural fluid was performed. The patient showed gradual improvement during the follow-up period. The temperature tended to decreased to $38^{\circ} \mathrm{C}$ from over $>39^{\circ} \mathrm{C}$. The inflammatory marker (i.e., CRP, PCT, IL-6, and SAA) levels decreased slightly. CT scan showed the pleural effusion reduced significantly. Meanwhile, the patient recovered from the hemorrhagic shock of gastrointestinal bleeding. Given the patient's dangerous and complicated condition, allogeneic stem-cell transplantation was considered after obtaining the informed consent of the patient and her parents. Under Cy+ATG precondition, the patient received peripheral stem-cell transplantation from her fully HLA matched sister. The doses of precondition treatment were $0.25 \mathrm{mg} / \mathrm{kg}$ for rabbit ATG (on day -5 to day -2 ); $50 \mathrm{mg} / \mathrm{kg} /$ day for cyclophosphamide (on days -5 to-2); and antiemetic, hydration, alkalization, diuretic, and liver protection. The patient received $1.25 \mathrm{mg} / \mathrm{kg}$ cyclosporine A (i.v. q12h) starting day -1, with the goal level in the range of $200-300 \mathrm{ng} / \mathrm{mL} ; 15 \mathrm{mg} / \mathrm{m}^{2} /$ day methotrexate on day +1 and 10 $\mathrm{mg} / \mathrm{m}^{2} /$ day methotrexate on day $+1,+3,+6$; and mycophenolate on day +7 to 45 for GVHD prophylaxis. On day +15 post-transplantation, the patient's'ANC was $0.5 \times 10^{9} / \mathrm{L}$ and continued to increase. G-CSF was discontinued 3 days after ANC became $>1 \times 10^{9} /$ L. Platelet engraftment occurred on day +35 . CT showed (Figure 1C) that pulmonary infiltrate became transiently poor shortly before neutrophil reached the normal value. Then, the patient was treated with broad-spectrum antibacterial (cefoperazone/sulbactam, linezolid) and antifungal therapies (caspofungin, liposomal amphotericin B). The patient kept normal temperature from day +18 . The patient's condition improved rapidly after HSCT and was discharged on day +55 . The patient'was discharged on day +55 . CT showed (Figure 1D) that lung condition improved markedly. The patient's blood routine test returned to normal (WBC of $6.5 \times 10^{9} / \mathrm{L}, \mathrm{Hb}$ of $100 \mathrm{~g} / \mathrm{L}$, and PLT of $104 \times 10^{9} / \mathrm{L}$ ) on day +72 . CT (Figure 1E)showed the condition of lung on day +81 .

\section{Discussion}

Sibling-donor HLA-matched HSCT is the main treatment of SAA, with the long-term survival rate in the range of $85 \%-97 \%$ [4]. Infection is the leading cause of death in patients with SAA treated with 
immunosuppressive therapy and HSCT. A prospective randomized trial from France showed the outcomes of 465 patients who received antithymocyte globulins plus CSA as first-line treatment. A total of 55 patients died during the study primarily because of infections (53\%) [5]. Febrile neutropenia (FN) in patients with SAA, especially in children, is extremely common. A study on 31 children with SAA showed that clinically documented infections account for 21 (55.26\%), bacteremia for 13 (34.21\%), and IFIs for 6 (15.78\%), with the overall mortality rate of $42 \%$ [6]. Gram-negative bacteria are the predominant causative organisms. Jung et al. [3] found that Gram-negative bacteria account for $77.1 \%$, and MDR bacteria occupied $30.3 \%$. MDR bacteria are prevalent in patients with neutropenia [7-9]. Increases on the antimicrobial resistance of the Gram-negative bacteria in severe infectious complications among patients with hematological malignancies, such as cephalosporin and/or carbapenem-resistant Enterobacteriaceae (CRE), MDR, and extended-spectrum beta-lactamase (ESBL) resistance. Meanwhile, fungal infection is a major infectious complication in immunocompromised patients. A prospective, observational study [20] found that the prevalence of IFI is $22.97 \%$ in persistent $F N$ in children with acute leukemia. The most common isolated fungi is Aspergillussp., followed by Candidasp. The mortality rate is $9.45 \%$. Therefore, infection is inevitable in patients with immunodeficiency.

The best strategy and timing of HSCT for patient with uncontrolled infection should be determined, particularly in patients with severe active infection. In the 2017 Chinese expert consensus on AA showed that active infection and bleeding are not recommended before HLA-compatible unrelated donor HSCT [14]. However, the British Society for Hematology recommended MSD HSCT for young and adult patients with severe AA; Additional details for the timing of transplantation for the patients with severe infection and hemorrhage are unavailable [4]. The "threshold" of the transplant time should be further discussed, especially for the patients with poor performance status.

HSCT is relatively challenging for the patients with serious infection and intensifying complications. Infections caused by various MDR bacteria increase the risk of death significantly. Ceftazidimeavibactam (CAZ-AVI) is a novel synthetic $\beta$-lactamase inhibitor combination for a range of MDR Gramnegative infection $[15,16]$, which was approved by the FDA in 2017. CAZ-AVI has been successfully used in patients with limited treatment options for complicated intra-abdominal infections and hospitalacquired, ventilator-associated pneumonia caused by CRE and other multidrug Gram-negative bacteria [17-19]. In the present study, the patient showed gradual improvement after treatment with CAZ-AVI and fosfomycin. The patient's temperature tended to be $38^{\circ} \mathrm{C}$. Inflammatory markers (i.e., WBC count, CRP level, and IL-6 level) decreased.

Invasive aspergillosis (IA) is the most common IFI following a hematopoietic cell transplant, with emerging cryptic species exhibiting resistance to commonly used antifungals, such as azoles. Voriconazole is the current gold standard drug for IA. AmB lipid complex showed efficacy in the secondline therapy of IA in adults and children. The statements above are the guidelines for IA treatment from the Infectious Diseases Society of America, the European Conference on Leukemia, and the European Society of Clinical Microbiology and Infectious Diseases [20]. In clinical practice, the drug combination of treatment is best and most effective choice on specific conditions. In the present report, the patient had 
fever, cough, and chest pain. The patient was positive in GM test, and CT showed characteristic changes in aspergillus ball. The result of culture test was negative. Voriconazole as the diagnostic driven treatment was used immediately after diagnosis but showed limited response. With the treatment using liposome amphotericin B and caspofungin as antifungals, the patient recovered gradually. Patient's CT scan showed that the size of the aspergillus ball reduced gradually.

For patients preparing for HSCT, having the complications of MDR bacterial and fungal infections at the same time is rare. HLA-matched peripheral HSCT remains the first line of treatment for SAA under positive and effective anti-infective therapy.

With the development of new drugs, update of the transplant concepts, and improvement of diagnosis and treatment, hematologists can fully control the severe infection in patients with SAA. For patients with SAA combined with severe infection including multidrug resistance, HSCT may be the only effective treatment to promote granulocyte recovery and control disease progression.

\section{Declarations}

\section{- Ethics approval and consent to participate}

The study was approved by the institutional research ethics committee of Fujian Medical university Union hospital. The patient had signed the informed consent for the treatment.

\section{- Consent for publication}

All authors read and approved the final manuscript.

\section{- Availability of data and material}

We wish to share our data as a reference for peers.

\section{- Funding}

This work was supported by grants from Fujian Science and Technology Department: the project of Foreign Cooperation Project (Grants 201710004)

\section{- Competing interests}

There is no conflict of interest regarding the publication of this article.

\section{- Authors' contributions}

Nainong Li conceived and designed the therapeutic regimen for the case. Xiaofan Li participated in its design and coordination and helped to draft the manuscript. Xianling Chen carried out the treatment and 
performed the statistical analysis. Hua Li participated in the treatment and drafted the manuscript. and All authors read and approved the final manuscript.

\section{- Acknowledgements}

“Not applicable”

\section{Reference}

1 S. B. Killick, N. Bown, J. Cavenagh, I. Dokal, T. Foukaneli, A. Hill, P. Hillmen, R. Ireland, A. Kulasekararaj, G. Mufti, J. A. Snowden, S. Samarasinghe, A. Wood, J. C. Marsh, and Haematology British Society for Standards in, 'Guidelines for the Diagnosis and Management of Adult Aplastic Anaemia', Br J Haematol, 172 (2016), 187-207.

2 Torres HA, Bodey GP, Rolston KV, Kantarjian HM, Raad II, and Kontoyiannis DP, 'Infections in Patients with Aplastic Anemia: Experience at a Tertiary Care Cancer Center', Cancer, 98 (2003), 86-93.

3 Jung SM, Kim YJ, Ryoo SM, Sohn CH, Seo DW, Lim KS, and Kim WY, 'Cancer Patients with Neutropenic Septic Shock: Etiology and Antimicrobial Resistance', The Korean journal of internal medicine (2019).

4 S. Samarasinghe, P. Veys, A. Vora, and R. Wynn, 'Paediatric Amendment to Adult Bsh Guidelines for Aplastic Anaemia', Br J Haematol, 180 (2018), 201-05.

5 olivares, 'Tratamiento Exitoso De Una Fusariosis Diseminada En Un Paciente Neutropénico Febril Con Terapia Antifúngica Combinada De Voriconazol Más Anfotericina B Deoxicolato', (2018).

6 Samanta A, Chandra J, Kaur R, Anand R, Shukla S, and Mandal P, 'Clinical Profile and Microbiological Spectrum of Febrile Neutropenic Episodes in Children with Severe Aplastic Anemia', Journal of pediatric hematology/oncology (2019).

7 Garcia-Vidal C, Cardozo-Espinola C, Puerta-Alcalde P, Marco F, Tellez A, Agüero D, Romero-Santana F, Díaz-Beyá M, Giné E, Morata L, Rodríguez-Núñez O, Martinez JA, Mensa J, Esteve J, and Soriano A, 'Risk Factors for Mortality in Patients with Acute Leukemia and Bloodstream Infections in the Era of Multiresistance', PloS one, 13 (2018), e0199531.

8 Daef EA, Elsherbiny NM, Agban MN, Riad KF, and Mohammed LF, 'Bloodstream Infections in Febrile Neutropenic Pediatric Cancer Patients: Microbiological and Sepsis Biomarkers Insight', The Egyptian journal of immunology, 25 (2018), 21-34.

9 Cattaneo C, Di Blasi R, Skert C, Candoni A, Martino B, Di Renzo N, Delia M, Ballanti S, Marchesi F, Mancini V, Orciuolo E, Cesaro S, Prezioso L, Fanci R, Nadali G, Chierichini A, Facchini L, Picardi M, Malagola M, Orlando V, Trecarichi EM, Tumbarello M, Aversa F, Rossi G, and Pagano L, 'Bloodstream Infections in Haematological Cancer Patients Colonized by Multidrug-Resistant Bacteria', Annals of hematology, 97 (2018), 1717-26. 
10 Trecarichi EM, and Tumbarello M, 'Antimicrobial-Resistant Gram-Negative Bacteria in Febrile Neutropenic Patients with Cancer: Current Epidemiology and Clinical Impact', Current opinion in infectious diseases, 27 (2014), 200-10.

11 Trecarichi EM, Pagano L, Candoni A, Pastore D, Cattaneo C, Fanci R, Nosari A, Caira M, Spadea A, Busca A, Vianelli N, and Tumbarello M, 'Current Epidemiology and Antimicrobial Resistance Data for Bacterial Bloodstream Infections in Patients with Hematologic Malignancies: An Italian Multicentre Prospective Survey', Clinical microbiology and infection : the official publication of the European Society of Clinical Microbiology and Infectious Diseases, 21 (2015), 337-43.

12 Agarwal M, and Larson EL, 'Risk of Drug Resistance in Repeat Gram-Negative Infections among Patients with Multiple Hospitalizations', Journal of critical care, 43 (2018), 260-64.

13 Girmenia C, Bertaina A, Piciocchi A, Perruccio K, Algarotti A, Busca A, Cattaneo C, Raiola AM, Guidi S, Iori AP, Candoni A, Irrera G, Milone G, Marcacci G, Scimè R, Musso M, Cudillo L, Sica S, Castagna L, Corradini P, Marchesi F, Pastore D, Alessandrino EP, Annaloro C, Ciceri F, Santarone S, Nassi L, Farina C, Viscoli C, Rossolini GM, Bonifazi F, and Rambaldi A, 'Incidence, Risk Factors and Outcome of PreEngraftment Gram-Negative Bacteremia after Allogeneic and Autologous Hematopoietic Stem Cell Transplantation: An Italian Prospective Multicenter Survey', Clinical infectious diseases : an official publication of the Infectious Diseases Society of America, 65 (2017), 1884-96.

14 Chinese Society of Hematology Chinese Medical Association Red Blood Cell Disease Group, '[Chinese Expert Consensus on the Diagnosis and Treatment of Aplastic Anemia (2017)]', Zhonghua Xue Ye Xue Za Zhi, 38 (2017), 1-5.

15 Criscuolo M, and Trecarichi EM, 'Ceftazidime/Avibactam and Ceftolozane/Tazobactam for MultidrugResistant Gram Negatives in Patients with Hematological Malignancies: Current Experiences', Antibiotics (Basel, Switzerland), 9 (2020).

16 Jorgensen SCJ, Trinh TD, Zasowski EJ, Lagnf AM, Bhatia S, Melvin SM, Steed ME, Simon SP, Estrada SJ, Morrisette T, Claeys KC, Rosenberg JR, Davis SL, and Rybak MJ, 'Real-World Experience with Ceftazidime-Avibactam for Multidrug-Resistant Gram-Negative Bacterial Infections', Open forum infectious diseases, 6 (2019), ofz522.

17 Zhu XF, He HL, Wang SQ, Tang JY, Han B, Zhang DH, Wu LQ, Wu DP, Li W, Xia LH, Zhu HL, Liu F, Shi HX, Zhang X, Zhou F, Hu JD, Fang JP, Chen XQ, Ye TZ, Liang YM, Jin J, and Zhang FK, 'Current Treatment Patterns of Aplastic Anemia in China: A Prospective Cohort Registry Study', Acta haematologica, 142 (2019), 162-70.

18 Guimarães T, Nouér SA, Martins RCR, Perdigão Neto LV, Martins WMBS, Narciso Barbosa AC, Ferreira ALP, Costa SF, and Gales AC, 'Enterobacterialesceftazidime-Avibactam as Salvage Therapy for Infections Caused by Coresistant to Carbapenems and Polymyxins', Antimicrobial agents and chemotherapy, 63 (2019). 
19 Karlowsky JA, Kazmierczak KM, Bouchillon SK, de Jonge BLM, Stone GG, and Sahm DF, 'In Vitro Activity of Ceftazidime-Avibactam against Clinical Isolates of Enterobacteriaceae and Pseudomonas Aeruginosa Collected in Asia-Pacific Countries: Results from the Inform Global Surveillance Program, 2012 to 2015', Antimicrobial agents and chemotherapy, 62 (2018).

20 M. P. Ledoux, B. Guffroy, Y. Nivoix, C. Simand, and R. Herbrecht, 'Invasive Pulmonary Aspergillosis', Semin Respir Crit Care Med, 41 (2020), 80-98.

\section{Figures}




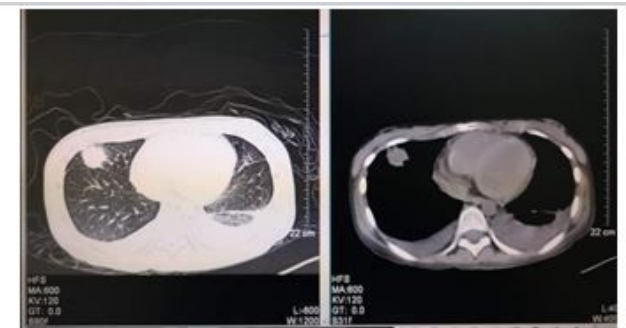

A. Before HSCT

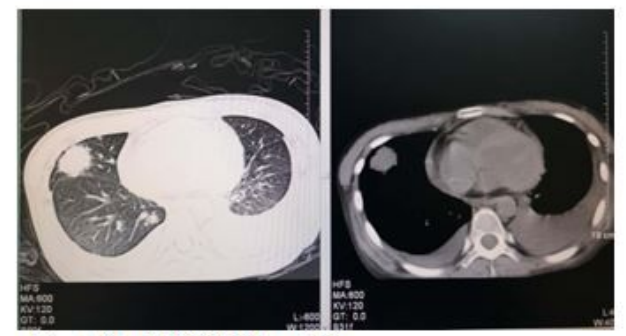

B. After HSCT, day +22

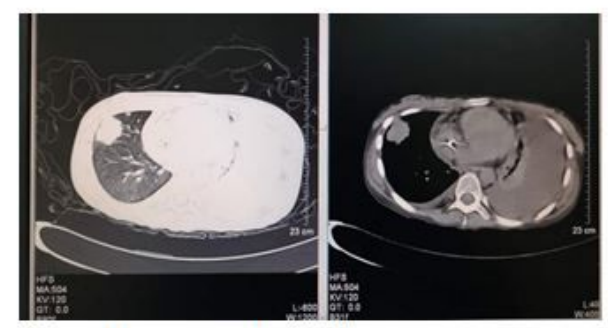

C. After HSCT, day +28

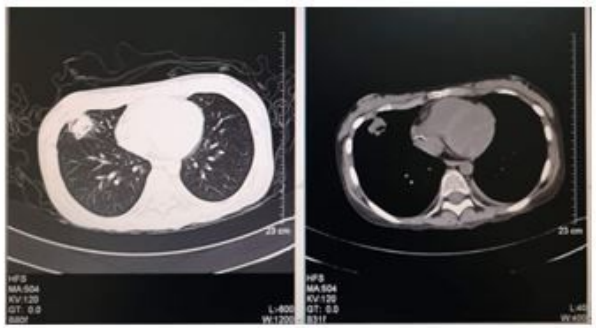

D. After HSCT, day +59

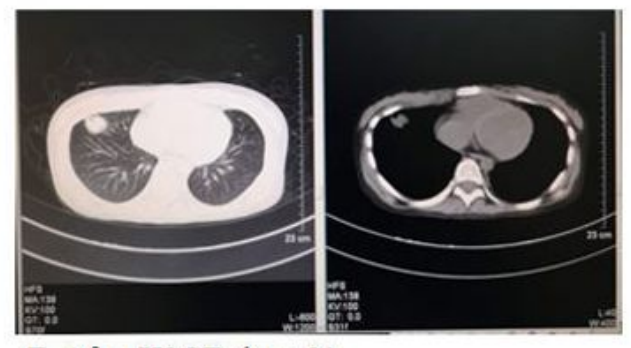

E. After HSCT, day +81

Figure 1

Course of chest CT examination. 